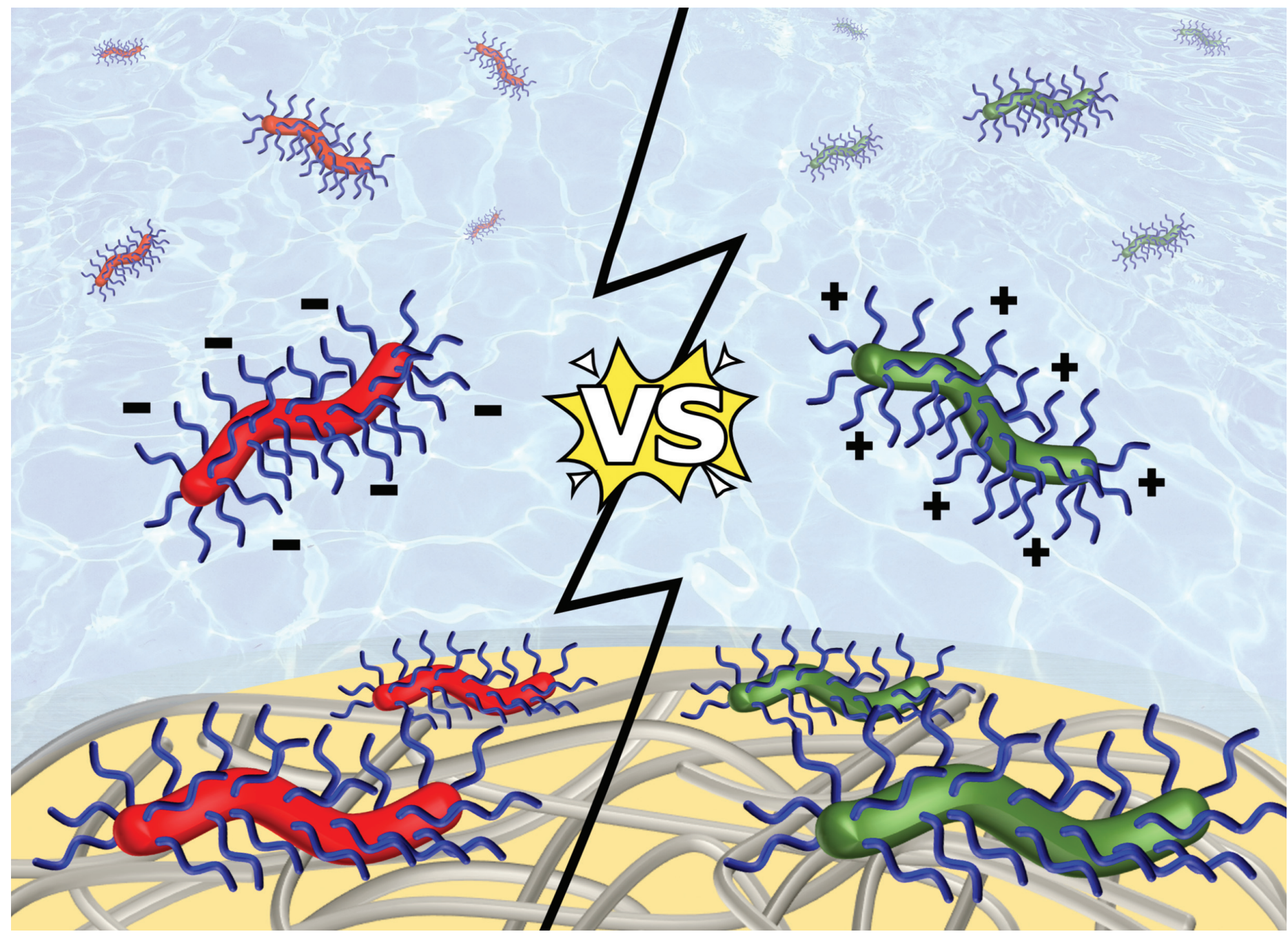

Highlighting research, led by Dr Fiona Hatton, from collaborations between the Departments of Materials at Loughborough University (UK), Chemistry at the University of Sheffield (UK), and Fibre and Polymer Technology at KTH Royal Institute of Technology (Sweden).

Investigating the adsorption of anisotropic diblock copolymer worms onto planar silica and nanocellulose surfaces using a quartz crystal microbalance

Dr Joakim Engström et al. have reported the adsorption of oppositely charged anisotropic diblock copolymer nanoparticles on silica, cellulose nanocrystal (CNC) and cellulose nanofibril (CNF) surfaces, using a quartz crystal microbalance. While electrostatic effects dominated the adsorption on CNC surfaces, adsorption on CNF surfaces gave unexpected results, suggesting the dominance of secondary interactions, such as hydrogen bonding, van der Waals forces, or possible covalent bond formation.

\section{As featured in:}

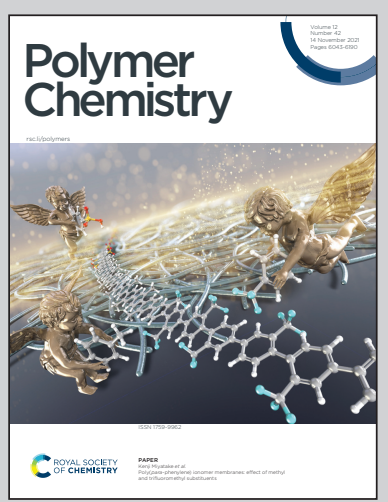

See Fiona L. Hatton et al., Polym. Chem., 2021, 12, 6088. 


\section{A) Check for updates}

Cite this: Polym. Chem., 2021, 12 6088

\title{
Investigating the adsorption of anisotropic diblock copolymer worms onto planar silica and nanocellulose surfaces using a quartz crystal microbalance $\uparrow$
}

\author{
Joakim Engström, (D) $\ddagger^{\mathrm{a}}$ Michael S. Reid, (D) ${ }^{\mathrm{b}}$ Emma E. Brotherton, ${ }^{\mathrm{c}}$ \\ Eva Malmström, (D) a Steven P. Armes (D) ${ }^{c}$ and Fiona L. Hatton $(\mathbb{D}) \S^{c}$
}

\begin{abstract}
Electrostatic adsorption of cationic polyelectrolytes onto anionic cellulosic substrates is an attractive route for facile surface modification of biorenewable materials. Recently, attention has focused on adsorbing cationic spherical diblock copolymer nanoparticles onto model cellulose and/or nanocellulosic substrates. Herein, we investigate physical adsorption of highly anisotropic copolymer worms bearing either anionic or cationic charge onto planar silica, cellulose nanocrystal (CNC) or cellulose nanofibril (CNF) surfaces using quartz crystal microbalance with dissipation monitoring. Electrostatic interactions dominate in the case of anionic silica and CNC surfaces because the adsorbed mass of cationic worms was greater than that of anionic worms. However, either anionic or cationic worms could be adsorbed onto in situ generated CNF substrates, suggesting that additional interactions were involved: hydrogen bonding, van der Waals forces, and possibly covalent bond formation. Scanning electron and atomic force microscopy studies of the dried planar substrates after adsorption experiments confirmed the presence of adsorbed copolymer worms. Finally, composite worm/CNF films exhibited restricted swelling behavior when immersed in water compared to reference CNF films, suggesting that the worms reinforce CNF films by acting as a physical crosslinker. This study is the first investigation of the physical adsorption of highly anisotropic diblock copolymer worms onto cellulosic surfaces.
\end{abstract}

Received 12th May 2021,

Accepted 5th September 2021

DOI: $10.1039 /$ d1py00644d

rsc.li/polymers

the development of cellulosic materials for value-added applications, ${ }^{2,4-6}$ such as energy-related devices, ${ }^{7}$ biomedical applications $^{8}$ and nanocomposites. ${ }^{9,10}$ However, unmodified cellulosic nanomaterials are hydrophilic in nature, undergo aggregation on drying, and are poorly compatible with hydrophobic components and matrices. Thus, judicious surface modification of nanocellulose using either small molecules or macromolecules is often required to impart or enhance desirable properties (i.e. colloidal stability, surface wettability, sufficiently hydrophobic character) for specific applications. ${ }^{11-15}$

CNFs are attractive nanocellulosic materials for the construction of free-standing films owing to their high aspect ratio, with mean lengths of the order of microns and diameters of around 5-20 nm, depending on the original source and production method. ${ }^{2,16}$ This anisotropy also leads to interesting aqueous dispersion properties: physical gels can be obtained at relatively low concentration $(<2 \% \mathrm{w} / \mathrm{w})$ under mildly acidic conditions $(\mathrm{pH}<3-4)$ and aggregation can be tuned by adding salt. ${ }^{17-20}$ Typically, CNFs are produced via TEMPO-mediated oxidation ${ }^{21,22}$ or carboxymethylation ${ }^{23}$ of cellulose fibres, followed by mechanical extraction of nano- 
fibrils from within the cell wall..$^{2,16,24,25}$ During TEMPOmediated oxidation, primary alcohols on the cellulose backbone (C6) are oxidized to form mainly anionic carboxylate groups and also a few aldehyde groups, which leads to chargestabilized CNFs with sodium counter-ions. ${ }^{22,26}$ CNCs are also anisotropic, rod-like nanoparticles, albeit with lower aspect ratios. Typically, they exhibit mean lengths of around 100-200 nm and diameters of approximately 5-20 nm. ${ }^{6}$ CNCs have interesting optical properties and can form a liquid crystalline phase above a certain critical concentration, but do not form gels as readily as CNFs. ${ }^{6,27}$ CNCs are most commonly prepared by sulfuric acid degradation of the amorphous regions of cellulose fibres to liberate the nanocrystals located within the interior. ${ }^{6,28}$ This results in the formation of sulfate halfesters at the CNC surface leading to charge-stabilized anionic particles. $^{6,28}$

Typically, nanocellulose modification is achieved by either physical adsorption of suitable ionic or non-ionic species, or by covalent grafting. ${ }^{11,13}$ The former approach is particularly attractive owing to its simplicity, use of mild conditions and cost-effectiveness. For example, block copolymers can be used to confer hydrophobic character or stimulus-responsive behavior. ${ }^{15}$ This is typically achieved using a diblock copolymer in which one block is designed to interact with the cellulose surface and the other block confers the desired property. Amphiphilic block copolymers are well-known for their propensity to self-assemble in aqueous solution. ${ }^{29}$ For example, cationic diblock copolymer micelles have been used to modify anionic cellulosic nanoparticles. ${ }^{30,31}$

Recently, polymerization-induced self-assembly (PISA) has gained widespread recognition as a robust and potentially scalable technique for the preparation of diblock copolymer nanoparticles at relatively high concentration (up to $50 \% \mathrm{w} / \mathrm{w}$ ). ${ }^{32,33}$ PISA involves chain extension of a soluble precursor block using a monomer that forms an insoluble second block in the reaction medium, thus driving in situ self-assembly to produce sterically-stabilized nanoparticles. ${ }^{32}$ PISA syntheses are most commonly conducted via reversible addition-fragmentation chain transfer (RAFT) polymerization. ${ }^{33}$ This approach has been utilized to prepare diblock copolymer nanoparticles for the surface modification of cellulose via either ionic ${ }^{31,34-36}$ or non-ionic ${ }^{37}$ interactions. For example, Carlsson et al. reported the preparation of cationic spherical nanoparticles (NPs) by RAFT-mediated emulsion polymerization of methyl methacrylate (MMA) for the modification of cellulose. ${ }^{34}$ The electrostatic adsorption of cationic NPs onto in situ prepared CNF surfaces was monitored using a quartz crystal microbalance (QCM). Subsequently, Engström et al. extended this study by preparing cationic latex NPs comprising MMA, n-butyl methacrylate (BMA) or $n$-butyl acrylate (BA) and also poly(MMA-coBA) NPs with an adjustable glass transition temperature $\left(T_{\mathrm{g}}\right){ }^{35,36}$ Using a low $T_{\mathrm{g}}$ hydrophobic core-forming block modified the adsorption behavior of such NPs, despite their common cationic stabilizer block. ${ }^{36}$ They also used QCM-D to confirm adsorption of the cationic latex particles to anionic cellulose surfaces, namely with cellulose nanofibrils adsorbed in situ. QCM-D is a useful technique which relies on the fact that quartz is piezoelectric and can oscillate at a certain frequency when an alternating electric current is applied with a frequency close to the resonant frequency. ${ }^{38,39}$ Adsorbed mass to the crystal surface is then observed as a decrease in frequency and the mass adsorbed can be calculated, as demonstrated by Sauerbrey in $1959 .{ }^{40}$ Dissipation due to the adsorption of a viscoelastic film is also monitored by evaluating the decay of the oscillation after rapid excitation. ${ }^{38,41}$

PISA enables the rational design of various copolymer morphologies, including worms, vesicles and framboidal vesicles. ${ }^{42}$ Anisotropic copolymer particles (worms) are gaining interest for use in applications such as drug delivery, rheology modifiers, to form gels, and as thermal or electrically conducting nanowires. ${ }^{43}$ Whereby often anisotropic particles outcompete their spherical counterparts, or simply cannot be compared (e.g., for nanowires applications). Of particular relevance to the present study, cationic diblock copolymer worms have been evaluated by Penfold et al. as flocculants for micron-sized silica particles. ${ }^{44}$ However, crosslinking of the worm cores was found to be necessary to ensure the survival of the initial copolymer morphology. Similarly, worm multilayers have been constructed at a planar silica surface via sequential adsorption of cationic and anionic worms (i.e., using the so-called 'layer-bylayer' approach). ${ }^{45}$ Although the rate of electrostatic adsorption of cationic worms at an anionic planar silica surface was demonstrated to be remarkably fast, high resolution kinetic studies using a well-established technique such as QCM were not undertaken. In the absence of added salt, the final surface coverage was less than $20 \%$, which is comparable to that reported for other cationic nanoparticles. ${ }^{35,36,46}$

There have been several reports of the adsorption of isotropic spherical diblock copolymer nanoparticles onto cellulosic surfaces. ${ }^{15}$ However, as far as we are aware, there have been no prior studies of the adsorption of highly anisotropic worms onto such substrates. The adsorption behaviour of anisotropic particles at surfaces is of interest since multiple orientations can be adopted, whereas isotropic particles offer only one orientation. Interparticle interactions and particle-surface interactions can influence how anisotropic particle organise when adsorbed to a surface. ${ }^{47}$ Surface coverage has been shown to be dependent on aspect ratio, for example high aspect ratios can reduce surface coverage. Spherical particles typically adsorbed irreversibly and do not adsorb on top of each other, forming a monolayer, while anisotropic particles with high aspect ratios are unlikely to form a monolayer, especially when they are flexible. Anisotropic copolymer nanoparticles can also provide mechanical reinforcement, as reported by Rieger and coworkers. ${ }^{48}$ Addition of $5-10 \mathrm{wt} \%$ of reinforcing anisotropic copolymer nanoparticle fillers in poly (n-butyl acrylate-co-acrylic acid) latex films improved mechanical properties (increased stiffness and strength) of the films. ${ }^{48}$ Therefore, the incorporation of anisotropic diblock copolymer nanoparticles within cellulose-based composite materials can offer significant enhancements over previously reported spherical particles. 
Herein, we use a highly convenient one-pot protocol $^{49}$ to prepare anionic $\mathrm{PGMA}_{25}-\mathrm{PGlyMA}_{45}$ diblock copolymer worms, whose cores can then be crosslinked using ethylenediamine to confer net cationic charge. Importantly, using the same copolymer worms before and after modification allows for direct comparison and avoids variation in copolymer worm properties that might be experienced if using different coronal blocks. We use a quartz crystal microbalance with dissipation (QCM-D) instrument to study the adsorption of either anionic worms or cationic worms onto an anionic planar silica surface, a spin-coated CNC surface and an in situ prepared CNF surface. After these adsorption experiments, the dried substrates were examined by either scanning electron microscopy (SEM) or atomic force microscopy (AFM). Finally, free-standing nanocomposite films comprising $\mathrm{CNF}$ and diblock copolymer worms were also prepared to investigate how the adsorbed worms influenced film swelling behavior.

\section{Results and discussion}

\section{Synthesis of PGMA 25 - PGlyMA $_{45}$ and PGMA $25-P(\text { GlyMA-EDA })_{45}$ copolymer worms}

Epoxy-functional diblock copolymer worms were prepared using a one-pot, three-step protocol as previously described elsewhere. ${ }^{49}$ Briefly, forced hydrolysis of glycidyl methacrylate (GlyMA; $10 \% \mathrm{w} / \mathrm{w}$ aqueous emulsion) was performed for $9 \mathrm{~h}$ at $85{ }^{\circ} \mathrm{C}$ to afford an $11.2 \% \mathrm{w} / \mathrm{w}$ aqueous solution of glycerol monomethacrylate (GMA), ${ }^{50}$ with ${ }^{1} \mathrm{H}$ NMR analysis indicating more than 99\% GlyMA conversion (see Fig. S1†). Subsequently, a commercially available RAFT chain transfer agent (CTA), 4-((((2-carboxyethyl)thio)carbonothioyl)thio)-4-cyanopentanoic acid (CECPA), and a low-temperature free radical initiator (VA-044) were added to the aqueous GMA solution, which was degassed and heated to $50{ }^{\circ} \mathrm{C}$ to produce the PGMA stabilizer block. After $3 \mathrm{~h}$, an aliquot of this polymerizing solution was removed for characterization by ${ }^{1} \mathrm{H}$ NMR spectroscopy and DMF GPC. High GMA conversion was achieved (99\%) and the resulting $\mathrm{PGMA}_{25}$ stabilizer block had an apparent numberaverage molecular weight, $M_{\mathrm{n}}$, of $7700 \mathrm{~g} \mathrm{~mol}^{-1}$ and dispersity, $Ð$, of 1.24 (relative to poly(methyl methacrylate) calibration standards). This $\mathrm{PGMA}_{25}$ precursor was then chain-extended via RAFT aqueous emulsion polymerization of GlyMA at $50{ }^{\circ} \mathrm{C}$ for $2 \mathrm{~h}$, targeting a $\mathrm{PGMA}_{25}-\mathrm{PGlyMA}_{45}$ diblock copolymer at $15 \% \mathrm{w} / \mathrm{w}$ solids. Mildly acidic conditions $(\mathrm{pH} 2.5-3.0)$ were chosen to avoid ionization of the carboxylic acid end-groups conferred by the CECPA RAFT agent, which is known to prevent the formation of diblock copolymer worms. ${ }^{49}$ More than 99\% GlyMA conversion was achieved and the resulting PGMA $_{25}-$ PGlyMA $_{45}$ diblock copolymer exhibited a relatively narrow molecular weight distribution $\left(M_{\mathrm{n}}=12900 \mathrm{~g} \mathrm{~mol}^{-1}\right.$, $Ð=1.33$ ) when characterized by DMF GPC (Fig. S2 $\dagger$ ). ${ }^{1} \mathrm{H}$ NMR spectra recorded for the in situ prepared GMA monomer, the water-soluble $\mathrm{PGMA}_{25}$ precursor and the final $\mathrm{PGMA}_{25}$ PGlyMA $_{45}$ worms are provided in the ESI (Fig. S1, S3 and S4, $\dagger$ respectively). A pure worm morphology was confirmed by TEM analysis of the dried $\mathrm{PGMA}_{25}-\mathrm{PGlyMA}_{45}$ diblock copolymer dispersion, see Fig. $1 \mathrm{~B}$.

The PGMA ${ }_{25}-$ PGlyMA $_{45}$ diblock copolymer worms were subsequently crosslinked using ethylenediamine (EDA) to ensure preservation of their highly anisotropic morphology, Fig. 1. The PGMA $_{25}-\mathrm{PGlyMA}_{45}$ diblock copolymer worms formed a free-standing hydrogel when prepared at $15 \% \mathrm{w} / \mathrm{w}$ solids owing to the formation of a 3D network structure. ${ }^{51,52}$ To ensure efficient stirring, this gel was diluted to $5 \% \mathrm{w} / \mathrm{w}$ with deionized water at $20{ }^{\circ} \mathrm{C}$ using a roller mill overnight to aid mixing. Excess EDA (EDA/GlyMA molar ratio $=5.0)$ was then added to the $5 \% \mathrm{w} / \mathrm{W} \mathrm{PGMA}_{25}-\mathrm{PGlyMA}_{45}$ diblock copolymer
A
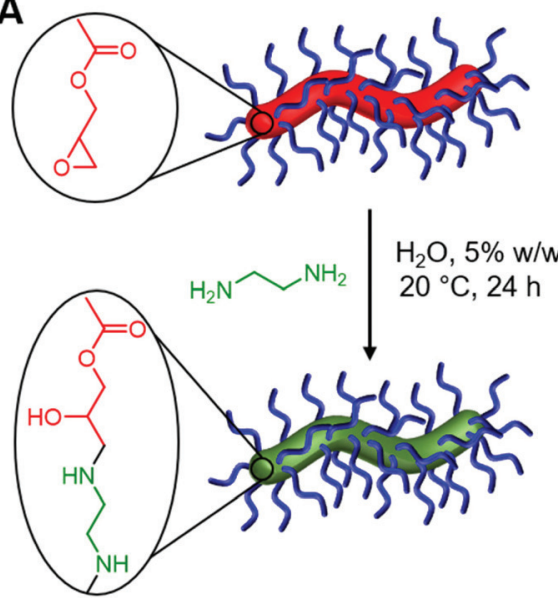
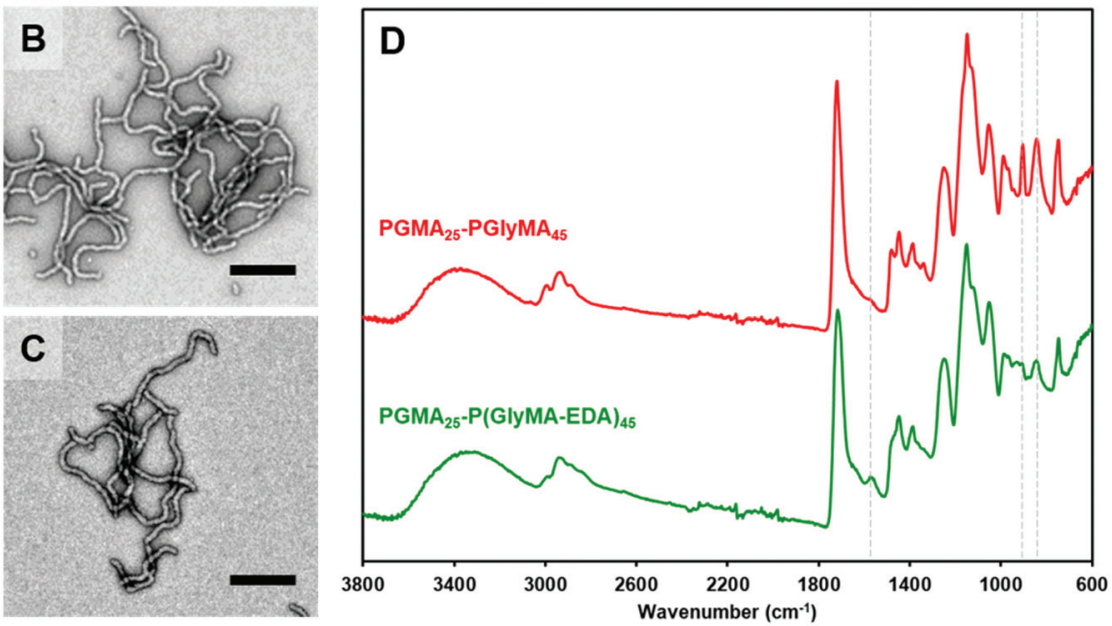

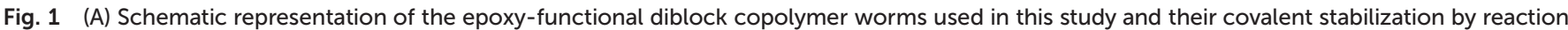

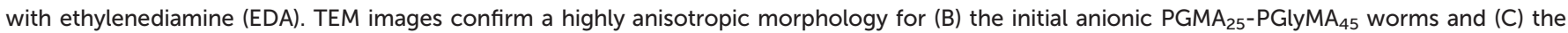

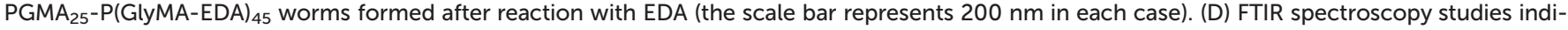
cate that the epoxy groups within the PGlyMA worm cores react with EDA, resulting in cationic crosslinked worms. 
dispersion, which was subsequently stirred at $20^{\circ} \mathrm{C}$ for $24 \mathrm{~h}$. The resulting crosslinked $\mathrm{PGMA}_{25}-\mathrm{P}(\text { GlyMA-EDA })_{45}$ worms were purified by exhaustive dialysis against deionized water to remove unreacted EDA and retention of the worm morphology was confirmed by TEM (Fig. 1C). Freeze-dried crosslinked PGMA $_{25}-\mathrm{P}(\text { GlyMA-EDA })_{45}$ worms were analyzed by FTIR spectroscopy (Fig. 1D). This technique indicated loss of the characteristic asymmetric vibrational modes for the epoxy ring (903 and $840 \mathrm{~cm}^{-1}$ ), and the appearance of a new absorption band at $1578 \mathrm{~cm}^{-1}$ that is characteristic of secondary amines. ${ }^{53}$ Elemental microanalyses of the freeze-dried PGMA $_{25}-$ PGlyMA $_{45}$ and $\mathrm{PGMA}_{25}-\mathrm{P}(\text { GlyMA-EDA })_{45}$ worms confirmed an increase in nitrogen content from $0 \%$ to $2.85 \%$, which indicates incorporation of the nitrogen-rich EDA reagent and implies successful crosslinking of the worm cores. Moreover, electrophoretic mobility measurements on $0.1 \% \mathrm{w} / \mathrm{w}$ aqueous dispersions of the linear and EDA-crosslinked worms conducted at $\mathrm{pH} 7$ indicated zeta potentials of $-30.7 \mathrm{mV}$ and $+18.8 \mathrm{mV}$, respectively. The anionic character observed prior to crosslinking arises from the ionized carboxylate groups located at the end of the PGMA stabilizer chains (originating from the CECPA RAFT agent). ${ }^{49}$ After crosslinking, the secondary amine groups within the worm cores become protonated; this leads to overall cationic character, as previously reported for EDA-crosslinked
PGMA $_{45}-$ PGlyMA $_{100}$ spheres. ${ }^{54}$ This methodology allows for the comparison of the same copolymer worm sample before (anionic) and after (cationic) modification, removing any variables that might results from using different coronal blocks to incorporate the charge.

\section{Worm adsorption onto planar silica and nanocellulose substrates using QCM-D}

The attempted adsorption of these two types of worms onto four different planar surfaces was evaluated by QCM-D (Fig. 2 and Fig. S5 $\dagger$ ). This technique can be used to analyze the kinetics and extent of adsorption with high resolution by relating the observed reduction in frequency, $\Delta f$, of an oscillating quartz crystal to an increase in mass, see Table $1 .^{55-57}$ Furthermore, in situ monitoring of the associated dissipation, $D$, provides additional information regarding the viscoelastic properties of the adsorbed layer. The relationship between frequency and dissipation $\left(\Delta D / \Delta f_{\mathrm{n}}\right)$ can also provide information regarding the degree of hydration of the adsorbed layer. Thus, for example, a cationic polyelectrolyte (PEI) forms a relatively stiff adsorbed layer that exhibits significantly lower dissipation than relatively soft, swollen nanoparticles. ${ }^{34,35,57}$ Here, we have used the well-known Sauerbrey model, ${ }^{40}$ see eqn (1), to estimate the mass adsorbed from the decrease in frequency.
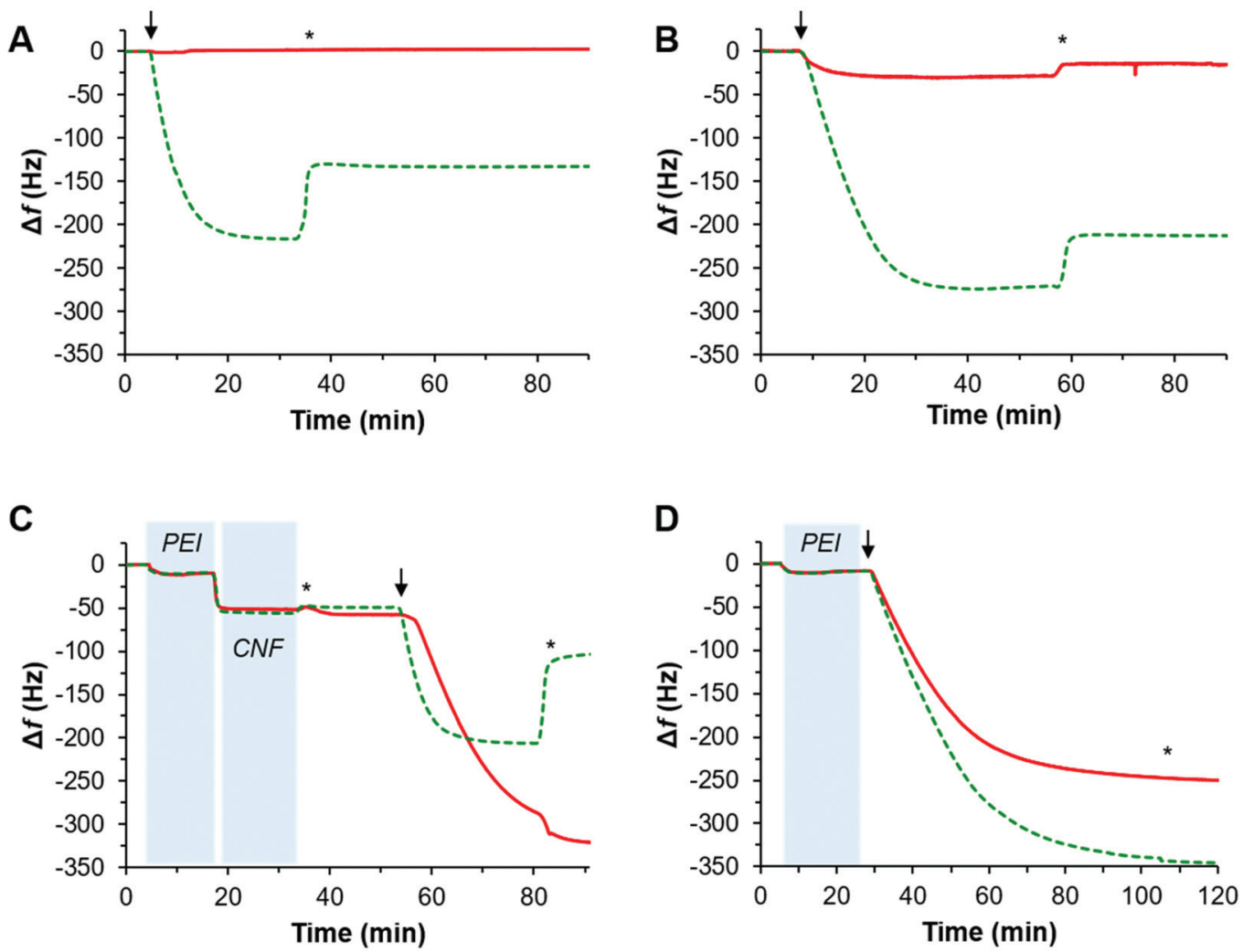

Fig. 2 QCM-D analysis of the frequency shift $(\Delta f)$ observed for the third overtone from adsorption of $0.1 \mathrm{~g} \mathrm{dm}^{-3}$ aqueous dispersions of anionic $P_{G M A_{25}-P G l y M A_{45} \text { worms (solid red lines) and cationic crosslinked PGMA }}-\mathrm{P}$ (GlyMA-EDA) 45 worms (dashed green lines) on the following substrates at a flow rate of $0.15 \mathrm{~mL} \mathrm{~min}^{-1}$ : (A) silica, (B) CNCs, (C) CNFs and (D) PEl. Arrows indicate when each worm dispersion was introduced into the flow chamber and an asterisk $\left(^{*}\right)$ indicates a washing step. For further details regarding the preparation of each substrate see the experimental section. Representative curves are presented from experiments run in duplicate. 
Table 1 Summary of adsorbed masses and dissipation data observed for anionic and cationic diblock copolymer worms adsorbed onto silica, CNC, in situ CNF and in situ PEI-coated surfaces during QCM-D experiments. Data were recorded after a rinsing step to ensure loosely bound species were removed

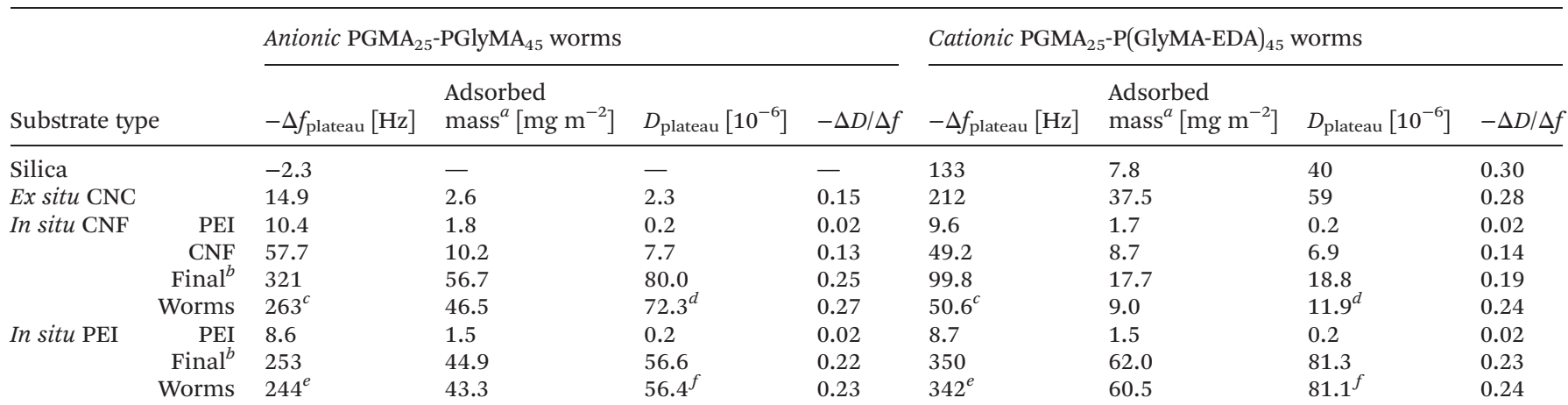

${ }^{a}$ Mass estimated from the Sauerbrey model using eqn (1). ${ }^{b}$ Final plateau value after rinsing step. ${ }^{c}$ Change in frequency calculated using $\Delta f=$ Final $\Delta f_{\text {plateau }}-\operatorname{CNF} \Delta f_{\text {plateau }}{ }^{d}$ Dissipation calculated using $D=$ Final $D_{\text {plateau }}-\operatorname{CNF} D_{\text {plateau }}{ }^{e}$ Change in frequency calculated using $\Delta f=$ Final $\Delta f_{\text {plateau }}-$ PEI $\Delta f_{\text {plateau }}{ }^{f}$ Dissipation calculated using $D=$ Final $D_{\text {plateau }}-$ PEI $D_{\text {plateau }}$.

However, it is worth noting that the Sauerbrey model is most appropriate for rigid adsorbed films, ${ }^{38,39}$ while the adsorbed material here show a large increase in dissipation and can be described as viscoelastic. Hence, the Sauerbrey model is likely to underestimate the actual mass adsorbed to these surfaces. Thus, we discuss the decrease in frequency rather than mass adsorbed, which has been calculated for completeness.

QCM-D crystals supplied by the manufacturer are coated with silica $\left(\mathrm{SiO}_{2}\right)$, leading to anionic surface charge in an aqueous environment. ${ }^{36}$ CNC surfaces were prepared by spincoating an aqueous CNC dispersion onto QCM-D crystals, followed by equilibration in water overnight. ${ }^{4}$ In contrast, CNF surfaces were prepared using an in situ method. ${ }^{36,58}$ Briefly, cationic PEI was adsorbed onto the silica substrate to induce charge reversal, ${ }^{58}$ prior to the electrostatic adsorption of anionic CNFs followed by rinsing with ultrapure water. For comparison, a PEI-coated crystal was also used as a cationic substrate in these adsorption experiments. Before introducing the aqueous worm dispersions $\left(0.1 \mathrm{~g} \mathrm{dm}^{-3}\right)$ into the QCM-D flow chamber, each substrate was equilibrated for at least 5 min using ultrapure Milli-Q water to produce a flat baseline.

\section{Silica surfaces}

As expected, there was negligible adsorption of the anionic $\mathrm{PGMA}_{25}-\mathrm{PGlyMA}_{45}$ diblock copolymer worms onto the anionic planar silica surface (Fig. 2A) since the electrostatic interactions are unfavorable in this case. In contrast, the cationic crosslinked $\mathrm{PGMA}_{25} \mathrm{P}(\text { GlyMA-EDA })_{45}$ worms exhibited a significant reduction in frequency $(>120 \mathrm{~Hz})$, indicating adsorption onto the silica surface. Using the Sauerbrey model (eqn (1)), the corresponding adsorbed mass was estimated to be $7.8 \mathrm{mg} \mathrm{m}^{-2}$ (see Table 1). No further adsorption occurred after approximately $20 \mathrm{~min}$, as indicated by a plateau in $\Delta f$. In this case, an $-\Delta D / \Delta f$ ratio of 0.3 indicated a relatively swollen layer of cationic crosslinked $\mathrm{PGMA}_{25} \mathrm{P}(\text { GlyMA-EDA })_{45}$ copolymer worms at the silica surface.
These data can be compared to that reported for the adsorption of high $T_{\mathrm{g}}$ cationic PMMA latex particles of $215 \mathrm{~nm}$ diameter, which exhibited a $-\Delta D / \Delta f$ of around 0.3 for a $\sim 75$ $\mathrm{Hz}$ reduction in frequency. ${ }^{36}$ Here, a significant increase in frequency occurred during the rinsing step (* in Fig. 2A), indicating that loosely bound worms were removed from the surface. This is consistent with the reduction in dissipation that occurs at $35 \mathrm{~min}$, see Fig. S5A. $\dagger$ SEM analysis of the dried substrates confirmed the absence of any adsorbed anionic $\mathrm{PGMA}_{25}$ PGlyMA $_{45}$ diblock copolymer worms, whereas adsorption of the cationic crosslinked $\mathrm{PGMA}_{25}-\mathrm{P}(\text { GlyMA-EDA })_{45}$ worms was observed, albeit at submonolayer coverage (see Fig. 3).

\section{Ex situ CNC surfaces}

The spin-coated CNC surfaces are highly anionic with typical charge densities of $0.08-0.350 \mathrm{mmol} \mathrm{g}^{-1}$. The anionic $\mathrm{PGMA}_{25}-\mathrm{PGlyMA}_{45}$ worms exhibited relatively weak adsorption to such surfaces: the initial frequency reduction of only $\sim 25$ $\mathrm{Hz}$ was reduced to $-10 \mathrm{~Hz}$ after rinsing (Fig. 2B). This latter value corresponds to an effective adsorbed amount of just $2.6 \mathrm{mg} \mathrm{m}^{-2}$ (Table 1). However, given the mutual repulsion between the worms and the substrate, no adsorption at all had been anticipated for this particular system. In contrast, there were much more of the cationic crosslinked $\mathrm{PGMA}_{25}-\mathrm{P}$ (GlyMA-EDA) ${ }_{45}$ worms adsorbed at the CNC surface: an initial $\Delta f$ of $-270 \mathrm{~Hz}$ prior to washing led to an equilibrium frequency of $-220 \mathrm{~Hz}$, which corresponds to an estimated adsorbed amount of $37.5 \mathrm{mg} \mathrm{m}^{-2}$. This is more than an order of magnitude higher than that observed for the anionic worms on the same surface, which is understandable given the strong electrostatic attractive forces involved. The $-\Delta D / \Delta f$ ratios calculated for the adsorbed layers of anionic and cationic worms were 0.15 and 0.27 respectively, which indicates that the former layer is significantly less viscoelastic. Moreover, the dissipation, $D$, is more than twenty times higher for the cationic 

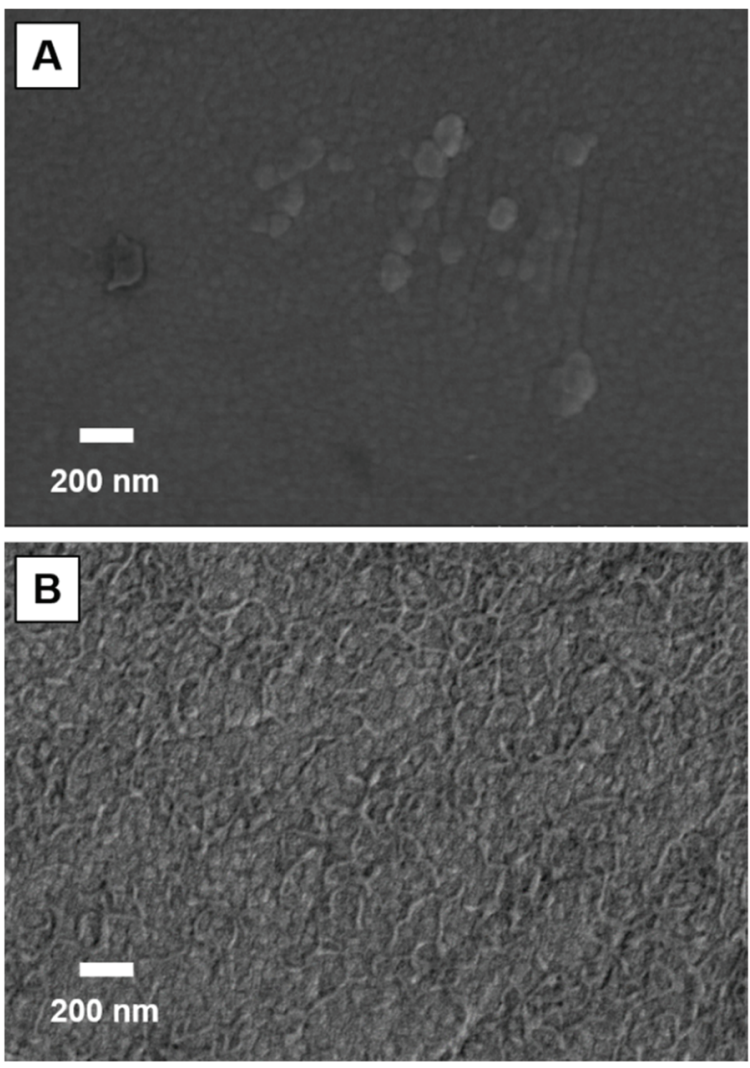

Fig. 3 Field emission SEM images recorded for dried planar silica substrates following $Q C M-D$ adsorption experiments using $(A)$ anionic linear $\mathrm{PGMA}_{25}-\mathrm{PGlyMA}_{45}$ worms and (B) cationic crosslinked $\mathrm{PGMA}_{25}-\mathrm{P}$ (GlyMA-EDA) 45 worms.

worms $\left(57.4 \times 10^{-6}\right)$ compared to that for the anionic worms $\left(2.8 \times 10^{-6}\right)$, see Fig. S5B. $\dagger$

Atomic force microscopy (AFM) was used to image the adsorbed worms on the CNC substrate, Fig. 4, due to difficulties imaging the CNC surfaces using SEM. The underlying surface is both dense and smooth, with directional alignment of the rod-like CNCs (Fig. 4A) and only a few anionic worms discernible at the surface. In contrast, there is no evidence for the underlying CNC substrate after adsorption of the cationic crosslinked $\mathrm{PGMA}_{25}-\mathrm{P}(\text { GlyMA-EDA })_{45}$ worms, which form a relatively densely packed adsorbed layer (Fig. 4B). These AFM observations are consistent with the QCM-D data (Table 1), with a significantly higher fractional surface coverage being obtained for the cationic worms compared to that achieved for the planar silica surface.

\section{In situ CNF surfaces}

When preparing the in situ CNF surface, the initial reduction in frequency observed after 5 min corresponds to the introduction of cationic polyelectrolyte (PEI) into the QCM-D chamber. This led to a plateau of around $-10 \mathrm{~Hz}$ as full PEI coverage was achieved, Fig. 2C. A further reduction in frequency was observed after 17-18 min owing to the adsorption of anionic CNFs onto the PEI-coated substrate. This produced a second $\Delta f$ plateau at around $-50 \mathrm{~Hz}$. After a rinsing step to remove extraneous CNF, diblock copolymer worms were then introduced into the QCM-D flow chamber after approximately 55 min. Adsorption of the cationic crosslinked $\mathrm{PGMA}_{25}-\mathrm{P}$ (GlyMA-EDA $)_{45}$ worms occurred, as indicated by a reduction in frequency to around $-200 \mathrm{~Hz}$. However, a rinsing step reduced this $\Delta f$ to an equilibrium value of $-99.8 \mathrm{~Hz}$, indicating removal of loosely bound worms from the CNF surface. The final adsorbed amount of cationic crosslinked $\mathrm{PGMA}_{25}-\mathrm{P}$ (GlyMA-EDA) 45 worms adsorbed at the in situ CNF/PEI surface was estimated to be $9.0 \mathrm{mg} \mathrm{m}^{-2}(\Delta f=50.6 \mathrm{~Hz})$, which is lower than that previously reported for spherical cationic nanoparticles. ${ }^{35,36}$ However, the cationic character of the crosslinked $\mathrm{PGMA}_{25}-\mathrm{P}(\text { GlyMA-EDA })_{45}$ worms arises from protonated amines located within the worm cores, which is reduced to some extent by the non-ionic PGMA stabilizer block. This interpretation is supported by observations made for EDAcrosslinked PGMA-PGlyMA spheres, which were less cationic
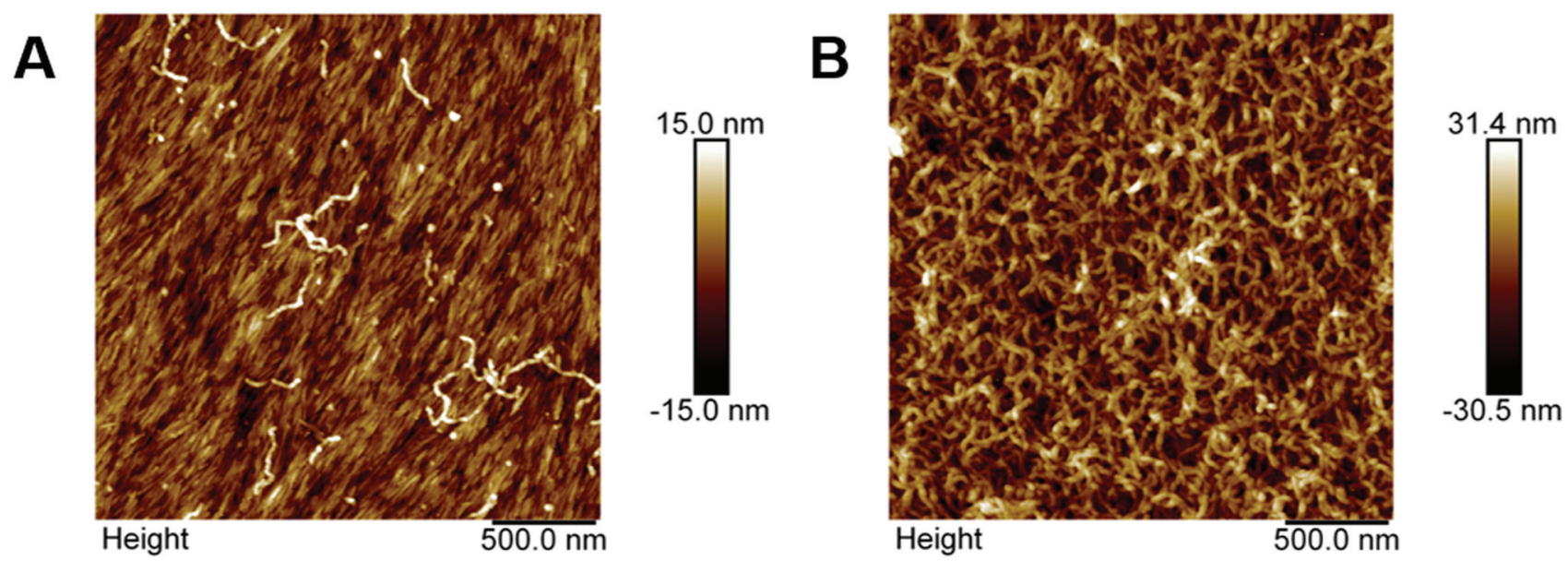

Fig. 4 AFM height images recorded for dried substrates following QCM-D experiments monitoring the adsorption of (A) anionic linear $P G M A_{25}-$ PGlyMA $_{45}$ worms and (B) cationic crosslinked PGMA $25-P(G l y M A-E D A)_{45}$ worms onto ex situ prepared CNC. 
than the equivalent spherical nanoparticles crosslinked using a longer diamine. ${ }^{54}$ Moreover, the adsorbed cationic worm layer is expected to exhibit strong electrostatic interactions with the anionic CNF, which may result in a denser adsorbed layer, causing charge reversal and preventing further adsorption of cationic worms.

Unexpectedly, the anionic $\mathrm{PGMA}_{25}-\mathrm{PGlyMA}_{45}$ worms adsorbed at the equivalent in situ CNF/PEI surface, with a much greater decrease in frequency observed. Given that both the CNFs and $\mathrm{PGMA}_{25}-\mathrm{PGlyMA}_{45}$ worms are anionic, minimal adsorption was anticipated owing to mutual electrostatic repulsion. However, the decrease in frequency observed for anionic PGMA $_{25}-$ PGlyMA $_{45}$ worms was $263 \mathrm{~Hz}$, which is much greater than that obtained for cationic worms on the same substrate $(50.6 \mathrm{~Hz})$. The increase in dissipation (Fig. S5C $\dagger$ ) after worm adsorption corresponds to a similar frequency shift (Fig. 2C) and comparable $-\Delta D / \Delta f$ ratios (see Table 1 ). In both cases, SEM studies of dried substrates revealed the presence of adsorbed worms (Fig. 5).

In principle, this counter-intuitive behavior could be related to the underlying layer of PEI chains. Given the rather stiff nature of the anisotropic CNF nanoparticles, ${ }^{35}$ it is perhaps unlikely that they would fully cover the electrostaticallyadsorbed PEI chains. Thus, adsorption of each worm type to a
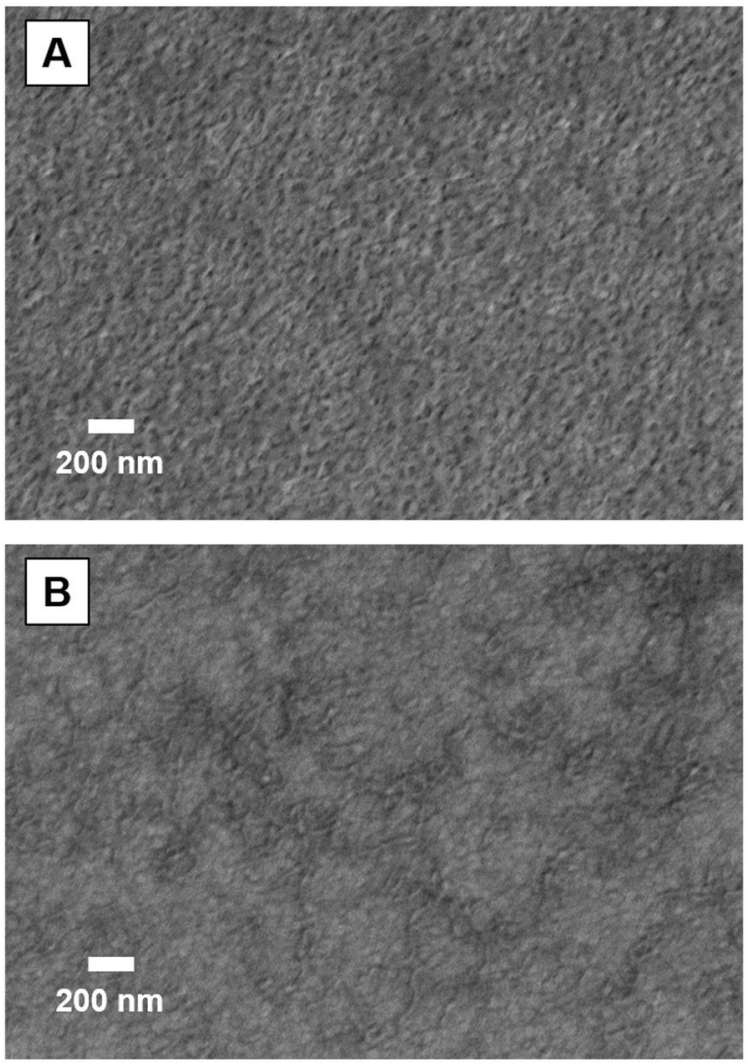

Fig. 5 Field emission SEM images recorded for dried substrates following QCM-D adsorption experiments of (A) anionic PGMA $25-P \mathrm{PGlyMA}_{45}$ worms and (B) cationic $\mathrm{PGMA}_{25}-\mathrm{P}(\mathrm{GlyMA}-\mathrm{EDA})_{45}$ worms onto in situ CNF surfaces.
PEI-coated surface was also investigated (see Fig. 2D). Surprisingly, the cationic crosslinked worms exhibited a larger $\Delta f$ than the anionic linear worms, and the corresponding estimated adsorbed amount was larger than for most of the other surfaces studied (Table 1). A relatively high adsorbed amount was expected for the anionic worms owing to strong electrostatic attractive forces, as previously observed for anionic silica nanoparticles on PEI. ${ }^{59}$ Thus, exposed regions of underlying PEI chains might explain why anionic worms can adsorb onto the anionic CNF surface.

However, the adsorption of cationic crosslinked worms onto the cationic PEI layer was higher than expected, suggesting that adsorption was governed by non-electrostatic interactions in this case. For example, hydrogen bonding may occur between the cis-diol groups present in the GMA repeat units and the amines (primary, secondary and tertiary) in the PEI chains, see Fig. 6. However, given that the two types of worms each have the same PGMA stabilizer block, similar degrees of hydrogen bonding might be expected. Another likely adsorption mechanism is the formation of covalent bonds between the PEI chains and the cationic crosslinked worms (Fig. 6).

It is worth noting that the increase in frequency before and after rinsing for cationic crosslinked worms on silica, ex situ CNC and in situ CNF surfaces was significant $(\Delta f=84,59$ and $103 \mathrm{~Hz}$, respectively). In principle, counter-ion exchange could account for part of this mass loss. Thus, we investigated the effect of counter-ion exchange after adsorption of the cationic crosslinked worms onto an in situ generated CNF surface, see Fig. S6. $\dagger$ After the rinsing step, a buffer solution was introduced into the QCM-D chamber. This resulted in a $\Delta f$ of -18 $\mathrm{Hz}$, which then returned to its previous value after a subsequent rinsing step with deionized water. This suggests that counter-ion exchange between the surface and the buffer solution was responsible for this observed reduction in frequency. This $\Delta f$ is considerably lower than that observed after adsorption of the cationic worms, confirming that the mass loss after rinsing is due to desorption of weakly-bound nano-objects rather than counter-ion exchange alone.

Worm-surface interactions appear to be governed by both electrostatic and non-ionic interactions, with differing behavior observed for CNF and CNC surfaces. The latter interactions include (i) hydrogen bonding owing to the cis-diol group in the GMA repeat units of the steric stabilizer block, (ii) potential covalent bond formation (see Fig. 6), and (iii) van der Waals interactions. Most notably, the strongest adsorption is observed for cationic crosslinked worms on the cationic PEI layer, which would not be the case if worm-surface interactions were dominated by electrostatic interactions.

\section{Worm/CNF nanocomposite films}

To further investigate worm/CNF interactions, vacuum filtration was used to produce free-standing worm/CNF nanocomposite films that mainly swell in the thickness direction. ${ }^{60}$ In this case the worms comprised $25 \%$ by mass of the nanocomposite film, as previously reported for latex/CNF composite 

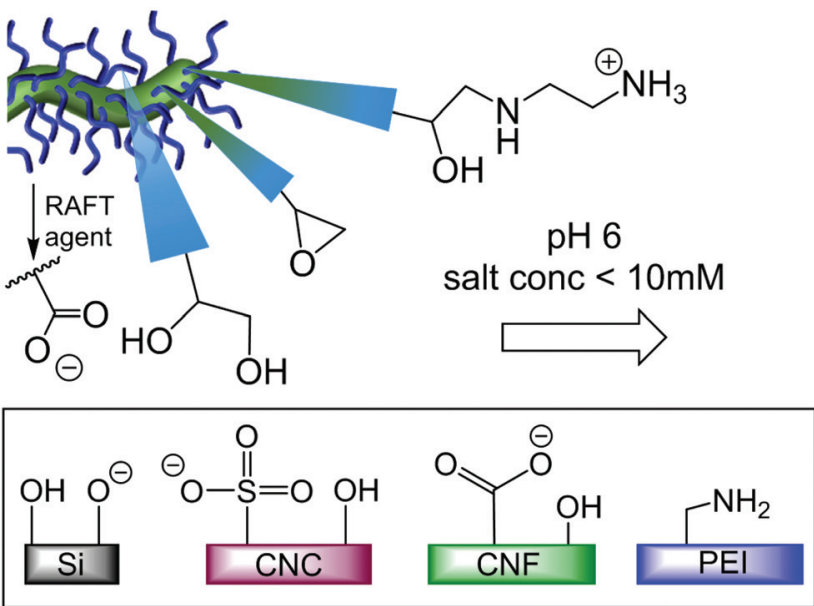

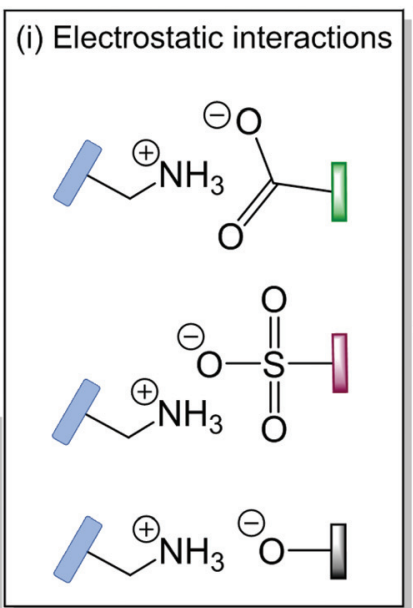

(ii) Hydrogen bonding

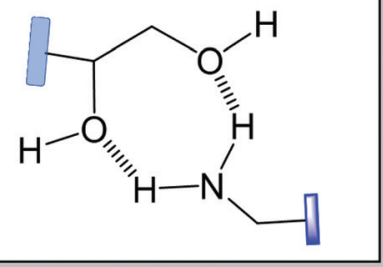

(iii) Covalent bond formation

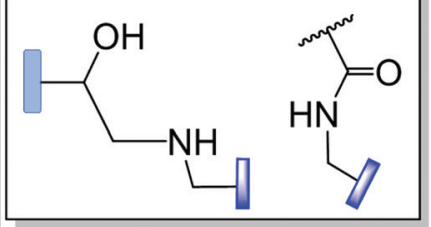

Fig. 6 Schematic representation of the various ways by which cationic crosslinked PGMA ${ }_{45}-P(G$ lyMA-EDA) 45 worms can interact with the four types of planar surfaces investigated in this study (silica, CNC, CNF, and PEI). Including (i) electrostatic interactions, (ii) hydrogen bonding and (iii) covalent bonding.

films. ${ }^{35}$ It is perhaps worth emphasizing that the hydrophilic nature and associated substantial swelling of CNF films is considered to be a significant limitation for their use in wet environments.

Depending on the drying technique, reference CNF films can swell up to more than $1000 \%$ in thickness. ${ }^{60,61}$ Reduced swelling indicates lower sensitivity to water and suggests network formation within the film. This can be achieved by introducing secondary interactions, such as $\mathrm{Ca}^{2+}$ counter-ions or covalent bonds between the film components. ${ }^{61,62}$ With the incorporation of anionic linear worms, the resulting films swelled up to $600 \%$ in thickness after equilibration for $24 \mathrm{~h}$ in water. In contrast, cationic crosslinked worms exhibited only a $200 \%$ increase in film thickness. Such restricted swelling suggests that electrostatic attractive forces between anionic $\mathrm{CNF}$ and the cationic worms result in a denser network. While, in QCM-D experiments (see Table 1, Fig. 2) a larger decrease in frequency was observed for anionic copolymer worms than the cationic worms, the adsorbed cationic worms are likely to form a denser adsorbed layer due to stronger electrostatic interactions. Although there is no such electrostatic attraction between anionic worms and anionic CNFs, the restricted swelling observed in this case is consistent with the QCM-D data and implies additional attractive forces between these two components, as discussed above (see Fig. 6).

On mixing the charged worms with the anionic CNFs, one might expect to observe flocculation, coacervate formation or retention of colloidal stability. In principle, the degree of dispersion can be assessed by evaluating the homogeneity of the resulting nanocomposite films by cross-sectional analysis using SEM, as reported previously for cationic latexes mixed with anionic CNFs. ${ }^{35,63}$ Accordingly, cross-sectioned worm/ CNF films were examined by SEM. The anionic $\mathrm{PGMA}_{25^{-}}$ PGlyMA $_{45}$ worms appear to be well-dispersed within such nanocomposites, affording a homogeneous layered structure (Fig. 7 and Fig. S7A $\dagger$ ). Moreover, FT-IR spectroscopy studies confirmed the presence of these worms, as indicated by the characteristic ester carbonyl band at $1730 \mathrm{~cm}^{-1}$, see Fig. S8. $\dagger$ In contrast, the cationic $\mathrm{PGMA}_{25}-\mathrm{P}(\text { GlyMA-EDA })_{45}$ worms exhibited some variance in the thickness direction, suggesting
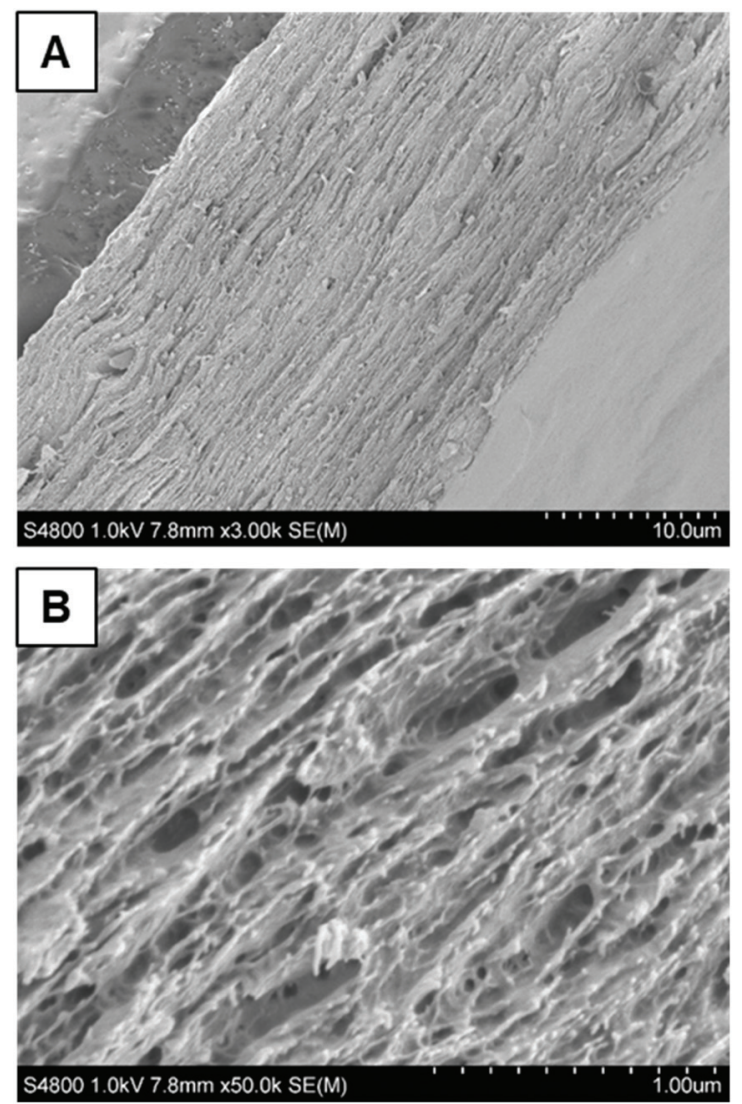

Fig. 7 Field emission SEM images recorded at (A) low and (B) high magnification for a cross-sectional area of a nanocomposite film comprising $25 \%$ w/w anionic PGMA $25-P \mathrm{PGlyMA}_{45}$ copolymer worms and $75 \% \mathrm{w} / \mathrm{w}$ CNFs. 
their flocculation prior to film formation (Fig. S7B $\dagger$ ). Indeed, such flocculation was indicated by the greater turbidity observed after mixing. However, relatively weak flocculation may not always be detectable by such measurements. Furthermore, flocculation might also occur during the vacuum filtration process used to create such nanocomposite films. In principle, small angle X-ray scattering (SAXS) might enable the degree of dispersion to be assessed during film formation, as suggested by prior spray brush studies ${ }^{64,65}$ and in situ PISA syntheses. ${ }^{66}$ However, this is beyond the scope of the present study. In summary, the restricted swelling behavior and high degree of dispersion suggest that these worm-CNF nanocomposites could be interesting materials for drug delivery or other hydrogel-type applications.

\section{Conclusions}

Epoxy-functional $\mathrm{PGMA}_{25}-\mathrm{PGlyMA}_{45}$ diblock copolymer worms were crosslinked using epoxy-amine chemistry. The original linear anionic $\mathrm{PGMA}_{25}-\mathrm{PGlyMA}_{45}$ worms and crosslinked cationic $\mathrm{PGMA}_{25}-\mathrm{P}(\mathrm{GlyMA}-\mathrm{EDA})_{45}$ worms were evaluated for their adsorption onto planar silica and nanocellulose (CNC, CNF) surfaces using QCM-D. Worm adsorption onto silica and ex situ CNC substrates was primarily governed by electrostatics: anionic worms exhibited minimal adsorption on either surface, whereas the adsorbed amounts of cationic worms were 7.8 and $37.5 \mathrm{mg}$ $\mathrm{m}^{-2}$, respectively. These observations suggest that the surface roughness and/or the CNC surface functionality also influences the adsorption behavior. The adsorption of copolymer worms onto an in situ generated CNF surface (using cationic PEI chains to achieve surface charge reversal of the silica substrate, hence enabling subsequent $\mathrm{CNF}$ adsorption) revealed relatively strong adsorption for both the anionic worms and the cationic worms, which cannot be explained in terms of electrostatic interactions. Indeed, QCM-D studies indicated that anionic and cationic worms adsorbed onto PEI-coated surfaces at adsorbed amounts of 43.3 and $60.5 \mathrm{mg} \mathrm{m}^{-2}$, respectively. This suggests that wormsurface interactions are dominated by hydrogen bonding (between the cis-diol unit in the GMA repeat units and amine groups in the PEI chains), van der Waals forces, or perhaps covalent bond formation via epoxy-amine chemistry, rather than electrostatics. However, further studies are required to confirm this hypothesis. Visual confirmation of worm adsorption onto planar silica and nanocellulose surfaces was confirmed by SEM and AFM studies. Finally, worm/CNF nanocomposites were prepared via vacuum filtration. Incorporation of $25 \% \mathrm{w} / \mathrm{w}$ anionic or cationic worms within the CNF films resulted in free-standing films. The degrees of swelling observed for such nanocomposite films were $600 \%$ and $200 \%$, respectively. This is much lower than that reported for CNF films alone $(>1000 \%)$, indicating that the incorporation of worms significantly reduces their swelling capacity. As far as we are aware, this is the first study of the adsorption of highly anisotropic diblock copolymer worms onto nanocellulose-based substrates.

\section{Experimental section}

\section{Materials}

4-(((2-(Carboxyethyl)thio)carbonothioyl)thio)-4-cyano-pentanoic acid (CECPA; 95\%) was kindly donated by Boron Molecular (Melbourne, Australia). Glycidyl methacrylate (GlyMA; 97\%), ethylenediamine (EDA, $\geq 99 \%$ ) and hydrochloric acid $(\mathrm{HCl}$; $37 \%$ ) were purchased from Sigma-Aldrich UK and used as received. VA-044 (VA-044; $\geq 97 \%$ ) was purchased from Wako Chemicals GmBH. Dimethyl sulfoxide- $d_{6}$ and $\mathrm{CD}_{3} \mathrm{OD}$ were purchased from Goss Scientific Instruments Ltd (Cheshire, UK). All other solvents were purchased from Fisher Scientific (Loughborough, UK) and used as received. Poly(ethylene imine) (PEI, $M_{\mathrm{n}}=60000 \mathrm{~g} \mathrm{~mol}^{-1}$ ) was purchased from Acros Organics. 2,2,6,6-tetramethyl-1-piperidinyloxy (TEMPO), sodium hypochlorite (14\% solution), sodium chlorite were obtained from Sigma-Aldrich AB and sodium bromide (99+\%) from Alfa Aesar. Phosphate buffer at pH 6.8 was prepared from aqueous solutions of sodium phosphate monobasic $\left(\mathrm{NaH}_{2} \mathrm{PO}_{4}, \geq 99 \%\right)$ and sodium phosphate dibasic $\left(\mathrm{Na}_{2} \mathrm{HPO}_{4}, \geq 99 \%\right)$ salts, both purchased from Sigma-Aldrich. Deionized water was used for all experiments. Biotech Cellulose Ester Dialysis Tubing was purchased from Spectrum Laboratories Inc. (USA) with a molecular weight cut-off (MWCO) of $50 \mathrm{kDa}$ and flat width of $31 \mathrm{~mm}(\varnothing=$ $20 \mathrm{~mm}$, vol $\left.=3.1 \mathrm{~mL} \mathrm{~cm}^{-1}\right)$. CNCs were prepared from cotton Whatman ashless filter aid via sulfuric acid hydrolysis according to Reid et al. ${ }^{6}$ The pulp used for the preparation of cellulose nanofibrils was a 'never-dried' dissolving pulp (60\% Norwegian spruce and $40 \%$ Scots Pine) kindly supplied by Domsjö Aditya Birla AB, Domsjö, Sweden. The preparation of cellulose nanofibrils was conducted via TEMPO-oxidation at $\mathrm{pH} 6.8$ in phosphate buffer to liberate the fibrils from the fibres using the method reported by Saito et al., ${ }^{21,67}$ achieving a charge density of $\sim 600 \mu \mathrm{eq} \mathrm{g}^{-1}$ as measured by conductometric titration. ${ }^{68}$ After TEMPO oxidation, the oxidized fibres were passed through a high-pressure homogenizer (Microfluidizer M-110EH, Microfluidics Corp, USA) by two passes through $400 \mu \mathrm{m}$ and $200 \mu \mathrm{m}$ chambers at 1000 bar and four passes through $200 \mu \mathrm{m}$ and $100 \mu \mathrm{m}$ at $1650 \mathrm{bar}$, to produce a gel at $0.89 \% \mathrm{w} / \mathrm{w}$ dry content, similar to the protocol reported by Cervin et al. ${ }^{69}$

\section{Characterization methods}

${ }^{1}$ H NMR spectroscopy. ${ }^{1} \mathrm{H}$ NMR spectra were recorded at room temperature using a Bruker Avance III HD $400 \mathrm{MHz}$ spectrometer using either $\mathrm{CD}_{3} \mathrm{OD}$ or $d_{6}$-DMSO.

Dynamic light scattering (DLS). A Malvern Zetasizer NanoZS instrument was used to determine zeta potentials $(\zeta)$ of the copolymer worms. All zeta potential $(\zeta)$ measurements were made on $0.2 \% \mathrm{w} / \mathrm{w}$ copolymer dispersions prepared using $1 \mathrm{mM} \mathrm{NaCl}$ solution as a background electrolyte. All data were averaged over three consecutive runs.

Gel permeation chromatography (GPC). Copolymer molecular weight distributions were assessed using a GPC set-up comprising two Agilent PL gel $5 \mu \mathrm{m}$ Mixed-C columns and a guard column connected in series to an Agilent 1260 Infinity GPC system operating at $60{ }^{\circ} \mathrm{C}$ and equipped with a refractive 
index detector and a UV-visible detector (set at $\lambda=309 \mathrm{~nm}$ ). The GPC eluent was HPLC-grade DMF containing $10 \mathrm{mM} \mathrm{LiBr}$

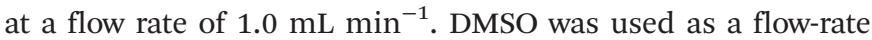
marker. Calibration was achieved using a series of ten nearmonodisperse poly(methyl methacrylate) standards (ranging in $M_{\mathrm{p}}$ from 625 to $618000 \mathrm{~g} \mathrm{~mol}^{-1}$ ). Chromatograms were analysed using Agilent GPC/SEC software.

Transmission electron microscopy (TEM). Copper/palladium TEM grids (Agar Scientific, UK) were coated in-house to yield a thin film of amorphous carbon. The grids were subjected to a glow discharge for $30 \mathrm{~s}$. Dilute aqueous copolymer dispersions $(10 \mu \mathrm{L}, 0.1 \% \mathrm{w} / \mathrm{w}$ solids) were subsequently placed onto freshly treated grids for $20 \mathrm{~s}$ and then carefully blotted with filter paper to remove excess solution. To ensure sufficient electron contrast, uranyl formate $(10.0 \mu \mathrm{L}$ of a $0.75 \% \mathrm{w} / \mathrm{w}$ solution $)$ was placed onto the sample-loaded grid for $20 \mathrm{~s}$ and then carefully blotted to remove excess stain. Each grid was then dried using a vacuum hose. Imaging was performed using a FEI Tecnai Spirit 2 microscope operating at $80 \mathrm{kV}$ and equipped with an Orius SC1000B camera.

Field emission scanning electron microscopy (SEM). QCM-D crystals were analyzed by SEM after worm adsorption followed by drying at room temperature in a humid chamber. A field emission Hitachi S-4800 microscope was used at an acceleration voltage of either $1.0 \mathrm{kV}$ or $3.0 \mathrm{kV}$ and images were acquired at various magnifications. QCM-D crystals were mounted onto metal stubs using carbon tape and coated with a $5 \mathrm{~nm}$ layer of Pt/Pd using a Cressington 208HR sputter coater.

Atomic force microscopy (AFM). AFM images were recorded using a MultiMode 8 (Bruker, Santa Barbara, CA, USA) AFM instrument in TappingMode with RTESP-150 cantilevers having a reported spring constant of $5 \mathrm{~N} \mathrm{~m}^{-1}$ and a resonant frequency of $150 \mathrm{kHz}$. Images of dried, spin-coated cellulose nanocrystals (CNCs) on QCM-D crystals were collected under ambient conditions prior to and after adsorption of the worms.

FT-IR spectroscopy. Spectra were recorded for freeze-dried copolymer worms at $20{ }^{\circ} \mathrm{C}$ (256 scans accumulated per spectrum) using a Thermo-Scientific Nicolet IS10 FT-IR spectrometer equipped with a Golden Gate Diamond ATR accessory. Spectra were recorded using 256 scans with a $4.0 \mathrm{~cm}^{-1}$ resolution, from 600 to $4000 \mathrm{~cm}^{-1}$. Spectra were also recorded for an aqueous dispersion of copolymer worms and for films comprising worms and cellulose nanofibrils using a PerkinElmer Spectrum 100 spectrometer equipped with a triglycine sulfate (TGS) detector. The instrument was equipped with a single reflection attenuated total reflection (ATR) Golden Gate accessory (Graseby Specac Ltd, Kent, UK) equipped with a temperature control unit (Specac, Heated Golden Gate Controller). FT-IR spectra were recorded from 600 to $4000 \mathrm{~cm}^{-1}$ at a resolution of $4.0 \mathrm{~cm}^{-1}$ and averaged over eight scans. Data were analyzed using Spectrum software v. 10.5.1 provided by PerkinElmer.

Quartz crystal microbalance with dissipation monitoring (QCM-D). A QCM-E4 instrument (Q-sense AB, Sweden) was used at a flow rate of $0.15 \mathrm{~mL} \mathrm{~min}^{-1}$. This instrument measures the change in resonant frequency of the crystal, which can be related to a change in mass owing to adsorption (or desorption). To convert this change in frequency into the corresponding change in adsorbed mass per area unit, the Sauerbrey model ${ }^{40}$ can be used for strongly-anchored adsorbed layers:

$$
m=C\left(\Delta f \times n^{-1}\right)
$$

where $C$ is a sensitivity constant, $-0.177\left(\left(\mathrm{mg} \mathrm{m}^{-2}\right) \times \mathrm{Hz}^{-1}\right), \Delta f$ is the change in resonance frequency $(\mathrm{Hz})$, and $n$ is the overtone number. The calculated mass includes both the solid adsorbed amount and any immobilized solvent within the adsorbed layer.

The QCM-D also detects the energy dissipation in the adsorbed layer, which is related to its viscoelastic properties. A thin, rigid film results in a relatively small change in dissipation, while a solvent-rich, viscoelastic film results in a larger change in dissipation. The dissipation factor, $D$, is defined as:

$$
D=E_{\text {dissipated }} / 2 \pi E_{\text {stored }}
$$

where $E_{\text {dissipated }}$ is the energy dissipated during one oscillation period and $E_{\text {stored }}$ is the energy stored in the oscillating system. Prior studies have shown that the Sauerbrey model is also valid for layers with higher dissipations and comparable to results obtained using more advanced models. ${ }^{58}$

\section{Synthesis}

Synthesis of PGMA $_{25}$-PGlyMA 4 diblock copolymer worms. The PGMA $_{25}-$ PGlyMA $_{45}$ worms were prepared using a one-pot protocol as described elsewhere. ${ }^{49}$ Briefly, GlyMA (2.0 g, $14.1 \mathrm{mmol}$ ) and water (18.0 g, $1.0 \mathrm{~mol}, 10 \% \mathrm{w} / \mathrm{w}$ GlyMA aqueous emulsion) were added to a round-bottomed flask equipped with a magnetic flea and a condenser. The initial aqueous emulsion was stirred for $9 \mathrm{~h}$ at $85{ }^{\circ} \mathrm{C}$ and eventually became a homogeneous aqueous solution, with 98\% GMA conversion being achieved as judged by ${ }^{1} \mathrm{H}$ NMR spectroscopy. After the reaction mixture had cooled to $50{ }^{\circ} \mathrm{C}$, CECPA $(0.215 \mathrm{~g}$, $0.70 \mathrm{mmol}$ ) was added directly to the reaction vessel and stirred at $50{ }^{\circ} \mathrm{C}$ for $2-3 \mathrm{~min}$ until complete dissolution had occurred. On cooling to $20^{\circ} \mathrm{C}$, VA-044 (57 $\mathrm{mg}, 0.17 \mathrm{mmol}$ ) was added to this reaction mixture, which was then degassed via $\mathrm{N}_{2}$ purge for $30 \mathrm{~min}$. The degassed reaction mixture was then heated to $50{ }^{\circ} \mathrm{C}$ for $3 \mathrm{~h}$, after which a small aliquot was extracted for analysis by ${ }^{1} \mathrm{H}$ NMR spectroscopy in $\mathrm{CD}_{3} \mathrm{OD}$ and DMF GPC studies. Previously degassed acidified water (15.4 mL, pH 3) and GlyMA (3.61 $\mathrm{mL}, 26.4 \mathrm{mmol}$ ) were added via syringe under $\mathrm{N}_{2}$ to afford a $15 \% \mathrm{w} / \mathrm{w}$ aqueous emulsion, which was heated at $50{ }^{\circ} \mathrm{C}$ for $1 \mathrm{~h}$. The final $\mathrm{PGMA}_{25}-\mathrm{PGlyMA}_{45}$ diblock copolymer was analyzed by ${ }^{1} \mathrm{H}$ NMR spectroscopy (in $d_{6}$-DMSO) and DMF GPC. The PGMA $25-\mathrm{PGlyMA}_{45}$ worms formed a physical gel at $15 \% \mathrm{w} / \mathrm{w}$ solids, which required dilution to $5 \% \mathrm{w} / \mathrm{w}$ using deionized water to produce a free-flowing aqueous dispersion.

Crosslinking of PGMA-PGlyMA diblock copolymer worms. The PGMA $_{25}-$ PGlyMA $_{45}$ worms were crosslinked directly in aqueous media. First, the original worm dispersion $(2.5 \mathrm{~g}$, $15 \% \mathrm{w} / \mathrm{w}$ ) was weighed into a glass jar and diluted with deionized water $(7.5 \mathrm{~g})$ with magnetic stirring to afford a $5.0 \%$ 
$\mathrm{w} / \mathrm{w}$ dispersion, which was then stirred for $48 \mathrm{~h}$ at $20^{\circ} \mathrm{C}$ to ensure a high degree of dispersion (no visible aggregates). Subsequently, ethylenediamine (EDA) (0.835 mL, $12.5 \mathrm{mmol})$ was added into a sample vial, to which the appropriate mass of worms was also added (10.0 g of a 5.0\% w/w dispersion, $2.5 \mathrm{mmol}$ epoxy groups), to give a target EDA/epoxy molar ratio of 5.0. This reaction mixture was magnetically stirred at $20{ }^{\circ} \mathrm{C}$ for $24 \mathrm{~h}$. The resulting aqueous dispersion was purified by exhaustive dialysis against deionized water for three days. The purified PGMA $_{45}-\mathrm{P}(\text { GlyMA-EDA })_{45}$ worms were characterized by DLS and zeta potential measurements. The EDA-crosslinked worms were isolated as a dry powder after freeze-drying from water overnight and characterized by elemental microanalysis and FTIR spectroscopy.

\section{QCM-D adsorption experiments}

Preparation of surfaces for QCM-D experiments. Silicacoated quartz crystals (Q-sense $\mathrm{AB}$, Sweden) were first rinsed with deionized water, then ethanol and once more with deionized water before drying under $\mathrm{N}_{2}$. The crystals were then placed in an air plasma cleaner (Model PDC 002, Harrick Scientific Corporation, NY, USA) under reduced air pressure for $120 \mathrm{~s}$ at $30 \mathrm{~W}$. The same protocol was used for all QCM-D crystals, prior to adsorption experiments and formation of CNC and CNF surfaces, as detailed below.

Ex situ CNC surfaces by spin-coating CNCs onto silica quartz crystals. Cleaned QCM-D crystals were spin coated with a layer CNCs without the addition of a polymer adhesion layer, following a previously reported method. ${ }^{4}$ In brief, QCM crystals were covered with a $3 \mathrm{w} / \mathrm{w} \%$ dispersion of CNCs and spun at $3000 \mathrm{rpm}$ for $30 \mathrm{~s}$ to dry (Model $\mathrm{KW}-4 \mathrm{~A}$ ), resulting in a dense CNC layer on the silica surface, as examined AFM. Before starting the adsorption experiments, the QCM-D crystals coated with CNCs were equilibrated overnight in deionised water to ensure a stable baseline and avoid drift due to swelling before the adsorption experiments commenced. ${ }^{4}$

In situ CNF surfaces generated during QCM-D experiments. The CNF surfaces were formed in situ by a two-step process. In the first step, an anchoring layer of poly(ethylene imine) (PEI) was adsorbed at $0.1 \mathrm{~g} \mathrm{dm}^{-3}$ in $10 \mathrm{mM} \mathrm{NaCl}$ at $\mathrm{pH} 10$ (solution $\mathrm{pH}$ was adjusted by addition of $10 \mathrm{mM} \mathrm{NaOH}$ ) to produce saturation coverage, followed by rinsing with deionized water. In the second step, a CNF dispersion $\left(0.1 \mathrm{~g} \mathrm{dm}^{-3}\right)$ was adsorbed at $\mathrm{pH} 7$, followed by rinsing with deionized water in accordance with a previously published protocol. ${ }^{58,70}$

Monitoring worm adsorption at planar surfaces by QCM-D. Worm adsorption at various planar surfaces was conducted as previously reported. ${ }^{58,70}$ A constant flow rate of $0.15 \mathrm{~mL} \mathrm{~min}{ }^{-1}$ was used for all experiments. Each surface was equilibrated for at least $5 \mathrm{~min}$ with deionized water. For experiments involving ex situ CNC surfaces, surfaces were equilibrated for $6 \mathrm{~h}$. An aqueous worm dispersion $\left(0.1 \mathrm{~g} \mathrm{dm}^{-3}\right.$ in $5 \mathrm{mM}$ sodium/potassium phosphate buffer; $\mathrm{pH}$ 6.8) was then introduced into the flow chamber. After worm adsorption had reached equilibrium, deionized water was introduced into the chamber until there was no further change in frequency and dissipation. This rinsing step ensured removal of any residual salt that might otherwise influence the adsorbed mass or surface topography after drying. After such adsorption experiments, each QCM-D crystal was removed from the chamber and allowed to dry under in a Petri dish in the presence of wet tissue to maintain relatively high ( $\sim 70-80 \%)$ humidity during drying. This precaution reduced the rate of water evaporation and thus prevented unwanted 'coffee ring' surface effects. The effect of varying the drying conditions had been previously explored for QCM-D studies of nanoparticle adsorption. ${ }^{36}$ All adsorption experiments were performed in duplicate and sometimes in triplicate.

\section{Nanocomposite worm-CNF films}

Formation of worm-CNF nanocomposite films. A $2 \% \mathrm{w} / \mathrm{w}$ aqueous CNF gel was prepared using deionized water and dispersed (116 mL, 0.26\% w/w) via high shear homogenization using an Ultraturrax stirrer at $10000 \mathrm{rpm}$ for $20 \mathrm{~min}$ in a $500 \mathrm{~mL}$ flask. The resulting CNF dispersion was degassed for 30 min under vacuum to remove any air bubbles. Following previously published protocols developed for cationic nanoparticles, ${ }^{35}$ worm-CNF nanocomposite films were prepared by adding an aqueous worm dispersions $\left(\sim 3 \mathrm{~g} \mathrm{dm}^{-3}\right)$ dropwise to target a $25 \% \mathrm{w} / \mathrm{w}$ worm loading in a final nanocomposite of either $100 \mathrm{mg}$ or $400 \mathrm{mg}$ dry weight depending on size. The CNF dispersion or worm-CNF dispersion was then mixed by magnetic stirring for $30 \mathrm{~min}$ prior to vacuum filtration through a glass filter funnel (7.2 cm in diameter) using a $0.65 \mu \mathrm{m}$ PVDF membrane (DVPP Millipore, USA) with a target film thickness of $30-70 \mu \mathrm{m}$ and grammage of $40-80 \mathrm{~g} \mathrm{~m}^{-2} \cdot{ }^{71,72}$ After filtration, the films were allowed to dry for at least $24 \mathrm{~h}$ in a Petri dish placed in a fumehood prior to either reswelling or being placed in an air-conditioned room at $23^{\circ} \mathrm{C}$ for $24 \mathrm{~h}$ maintained at $50 \%$ relative humidity prior to further characterization.

Swelling experiments on worm-CNF nanocomposite films. A piece of each nanocomposite film $\left(\sim 1 \times 2 \mathrm{~cm}^{-2}\right)$ and reference TEMPO-oxidized CNF film was dried at ambient temperature and then immersed in MilliQ water $(10 \mathrm{~mL})$ to allow equilibrium swelling to occur over $24 \mathrm{~h}^{60,61}$ Then, excess water was removed from the swollen film and its thickness was measured in the wet state. This value was normalized with respect to the initial dry film thickness to calculate the degree of swelling (DS in \%) using eqn (3). This dimensional change correlated well with the mass increase for the swollen film compared to the dry film. The reference TEMPO-oxidized CNF film exhibited a mean increase in film thickness of $1060 \pm 160 \%$ from triplicate experiments, which is consistent with previous literature data of $\sim 1000 \% .^{60}$

$$
\text { Degree of } \operatorname{swelling}(\%)=\frac{\text { thickness }_{\text {wet }}-\text { thickness }_{\mathrm{dry}}}{\text { thickness }_{\mathrm{dry}}} \times 100
$$

\section{Conflicts of interest}

There are no conflicts to declare. 


\section{Acknowledgements}

S.P.A. thanks the EPSRC for a four-year Established Career Particle Technology Fellowship (EP/R003009/1). J.E and E.M would like to acknowledge the Knut and Alice Wallenberg foundation through the Wallenberg Wood Science Centre (WWSC) for financial support. We thank Boron Molecular (Melbourne, Australia) for the kind gift of the dicarboxylic acid RAFT agent (CECPA) and Domsjö Aditya Birla AB (Domsjö, Sweden) for donating the 'never dried' cellulose pulp used in this study. Dr Svetomir Tzokov (University of Sheffield, UK) is thanked for carbon-coating the TEM grids.

\section{References}

1 D. Klemm, B. Heublein, H.-P. Fink and A. Bohn, Angew. Chem., Int. Ed., 2005, 44, 3358-3393.

2 D. Klemm, F. Kramer, S. Moritz, T. Lindström, M. Ankerfors, D. Gray and A. Dorris, Angew. Chem., Int. Ed., 2011, 50, 5438-5466.

3 B. P. Mooney, Biochem. J., 2009, 418, 219-232.

4 E. J. Foster, R. J. Moon, U. P. Agarwal, M. J. Bortner, J. Bras, S. Camarero-Espinosa, K. J. Chan, M. J. D. Clift, E. D. Cranston, S. J. Eichhorn, D. M. Fox, W. Y. Hamad, L. Heux, B. Jean, M. Korey, W. Nieh, K. J. Ong, M. S. Reid, S. Renneckar, R. Roberts, J. A. Shatkin, J. Simonsen, K. Stinson-Bagby, N. Wanasekara and J. Youngblood, Chem. Soc. Rev., 2018, 47, 2609-2679.

5 K.-Y. Lee, G. Buldum, A. Mantalaris and A. Bismarck, Macromol. Biosci., 2014, 14, 10-32.

6 M. S. Reid, M. Villalobos and E. D. Cranston, Langmuir, 2016, 33, 1583-1598.

7 X. Du, Z. Zhang, W. Liu and Y. Deng, Nano Energy, 2017, 35, 299-320.

8 M. Jorfi and E. J. Foster, J. Appl. Polym. Sci., 2015, 132, 41719.

9 H. Kargarzadeh, M. Mariano, J. Huang, N. Lin, I. Ahmad, A. Dufresne and S. Thomas, Polymer, 2017, 132, 368-393.

10 A. Sharma, M. Thakur, M. Bhattacharya, T. Mandal and S. Goswami, Biotechnol. Rep., 2019, 21, e00316.

11 F. Rol, M. N. Belgacem, A. Gandini and J. Bras, Prog. Polym. Sci., 2019, 88, 241-264.

12 D. Roy, M. Semsarilar, J. T. Guthrie and S. Perrier, Chem. Soc. Rev., 2009, 38, 2046-2064.

13 Y. Habibi, Chem. Soc. Rev., 2014, 43, 1519-1542.

14 S. Wohlhauser, G. Delepierre, M. Labet, G. Morandi, W. Thielemans, C. Weder and J. O. Zoppe, Macromolecules, 2018, 51, 6157-6189.

15 F. L. Hatton, E. Malmström and A. Carlmark, Eur. Polym. J., 2015, 65, 325-339.

16 R. J. Moon, A. Martini, J. Nairn, J. Simonsen and J. Youngblood, Chem. Soc. Rev., 2011, 40, 3941-3994.

17 L. Mendoza, W. Batchelor, R. F. Tabor and G. Garnier, J. Colloid Interface Sci., 2018, 509, 39-46.
18 A. B. Fall, S. B. Lindström, O. Sundman, L. ödberg and L. Wågberg, Langmuir, 2011, 27, 11332-11338.

19 M. Nordenström, A. Fall, G. Nyström and L. Wågberg, Langmuir, 2017, 33, 9772-9780.

20 H. Fukuzumi, R. Tanaka, T. Saito and A. Isogai, Cellulose, 2014, 21, 1553-1559.

21 T. Saito, Y. Nishiyama, J.-L. Putaux, M. Vignon and A. Isogai, Biomacromolecules, 2006, 7, 1687-1691.

22 A. Isogai, T. Saito and H. Fukuzumi, Nanoscale, 2011, 3, 7185.

23 L. Wågberg, G. Decher, M. Norgren, T. Lindström, M. Ankerfors and K. Axnäs, Langmuir, 2008, 24, 784-795.

24 A. F. Turbak, F. W. Snyder and K. R. Sandberg, in J. Appl. Polym. Sci., Appl. Polym. Symp, United States, 1983, vol. 37, pp. 815-827.

25 B. G. Rånby, Acta Chem. Scand., 1949, 3, 649-650.

26 A. Isogai, T. Hänninen, S. Fujisawa and T. Saito, Prog. Polym. Sci., 2018, 86, 122-148.

27 J. P. F. Lagerwall, C. Schütz, M. Salajkova, J. Noh, J. H. Park, G. Scalia and L. Bergström, NPG Asia Mater., 2014, 6, e80.

28 S. Beck-Candanedo, M. Roman and D. G. Gray, Biomacromolecules, 2005, 6, 1048-1054.

29 Y. Mai and A. Eisenberg, Chem. Soc. Rev., 2012, 41, 59695985.

30 M. Wang, A. Olszewska, A. Walther, J.-M. Malho, F. H. Schacher, J. Ruokolainen, M. Ankerfors, J. Laine, L. A. Berglund, M. Österberg and O. Ikkala, Biomacromolecules, 2011, 12, 2074-2081.

31 A. Boujemaoui, C. Cobo Sanchez, J. Engström, C. Bruce, L. Fogelström, A. Carlmark and E. Malmström, ACS Appl. Mater. Interfaces, 2017, 9, 35305-35318.

32 S. L. Canning, G. N. Smith and S. P. Armes, Macromolecules, 2016, 49, 1985-2001.

33 F. D’Agosto, J. Rieger and M. Lansalot, Angew. Chem., 2020, 59, 2-27.

34 L. Carlsson, A. Fall, I. Chaduc, L. Wågberg, B. Charleux, E. Malmström, F. D’Agosto, M. Lansalot and A. Carlmark, Polym. Chem., 2014, 5, 6076-6086.

35 J. Engström, F. L. Hatton, L. Wågberg, F. D’Agosto, M. Lansalot, E. Malmström and A. Carlmark, Polym. Chem., 2017, 8, 1061-1073.

36 J. Engström, T. Benselfelt, L. Wågberg, F. D’Agosto, M. Lansalot, A. Carlmark and E. Malmström, Nanoscale, 2019, 11, 4287-4302.

37 F. L. Hatton, M. Ruda, M. Lansalot, F. D’Agosto, E. Malmström and A. Carlmark, Biomacromolecules, 2016, 17, 1414-1424.

38 M. C. Dixon, J. Biomol. Tech., 2008, 19, 151-158.

39 I. Reviakine, D. Johannsmann and R. P. Richter, Anal. Chem., 2011, 83, 8838-8848.

40 G. Sauerbrey, Z. Phys., 1959, 155, 206-222.

41 M. Rodahl, F. Höök, A. Krozer, P. Brzezinski and B. Kasemo, Rev. Sci. Instrum., 1995, 66, 3924-3930.

42 N. J. Warren and S. P. Armes, J. Am. Chem. Soc., 2014, 136, 10174-10185. 
43 J. C. Foster, S. Varlas, B. Couturaud, Z. Coe and R. K. O'Reilly, J. Am. Chem. Soc., 2019, 141, 2742-2753.

44 N. J. W. Penfold, Y. Ning, P. Verstraete, J. Smets and S. P. Armes, Chem. Sci., 2016, 7, 6894-6904.

45 N. J. W. Penfold, A. J. Parnell, M. Molina, P. Verstraete, J. Smets and S. P. Armes, Langmuir, 2017, 33, 14425-14436.

46 M. R. Talingting, Y. Ma, C. Simmons and S. E. Webber, Langmuir, 2000, 16, 862-865.

47 P. Viot, G. Tarjus, S. M. Ricci and J. Talbot, J. Chem. Phys., 1998, 97, 5212.

48 R. Albigès, P. Klein, S. Roi, F. Stoffelbach, C. Creton, L. Bouteiller and J. Rieger, Polym. Chem., 2017, 8, 4992.

49 F. L. Hatton, A. M. Park, Y. R. Zhang, G. D. Fuchs, C. K. Ober and S. P. Armes, Polym. Chem., 2019, 10, 194-200.

50 L. P. D. Ratcliffe, A. J. Ryan and S. P. Armes, Macromolecules, 2013, 46, 769-777.

51 J. R. Lovett, M. J. Derry, P. C. Yang, F. L. Hatton, N. J. Warren, P. W. Fowler and S. P. Armes, Chem. Sci., 2018, 9, 7138-7144.

52 F. L. Hatton, M. J. Derry and S. P. Armes, Polym. Chem., 2020, 6343-6355.

53 R. A. Heacock and L. Marion, Can. J. Chem., 1956, 34, 1782-1795.

54 F. L. Hatton, J. R. Lovett and S. P. Armes, Polym. Chem., 2017, 8, 4856-4868.

55 Q. Chen, S. Xu, Q. Liu, J. Masliyah and Z. Xu, Adv. Colloid Interface Sci., 2016, 233, 94-114.

56 T. Saarinen, M. Österberg and J. Laine, J. Dispersion Sci. Technol., 2009, 30, 969-979.

57 A. L. J. Olsson, I. R. Quevedo, D. He, M. Basnet and N. Tufenkji, ACS Nano, 2013, 7, 7833-7843.

58 C. Aulin, I. Varga, P. M. Claesson, L. Wågberg and T. Lindström, Langmuir, 2008, 24, 2509-2518.
59 C. Peng, Y. S. Thio, R. A. Gerhardt, H. Ambaye and V. Lauter, Chem. Mater., 2011, 23, 4548-4556.

60 F. L. Hatton, J. Engström, J. Forsling, E. Malmström and A. Carlmark, RSC Adv., 2017, 7, 14947-14958.

61 T. Benselfelt, J. Engström and L. Wågberg, Green Chem., 2018, 20, 2558-2570.

62 M. Shimizu, T. Saito and A. Isogai, J. Memb. Sci., 2016, 500, 1-7.

63 J. Engström, A. M. Jimenez and E. Malmström, Nanoscale, 2020, 12, 6462-6471.

64 J. Engström, C. J. Brett, V. Körstgens, P. MüllerBuschbaum, W. Ohm, E. Malmström and S. V. Roth, Adv. Funct. Mater., 2020, 30, 1-9.

65 W. Ohm, A. Rothkirch, P. Pandit, V. Körstgens, P. MüllerBuschbaum, R. Rojas, S. Yu, C. J. Brett, D. L. Söderberg and S. V. Roth, J. Coat. Technol. Res., 2018, 15, 759-769.

66 E. E. Brotherton, F. L. Hatton, A. A. Cockram, M. J. Derry, A. Czajka, E. J. Cornel, P. D. Topham, O. O. Mykhaylyk and S. P. Armes, J. Am. Chem. Soc., 2019, 141, 13664-13675.

67 T. Saito, M. Hirota, N. Tamura, S. Kimura, H. Fukuzumi, L. Heux and A. Isogai, Biomacromolecules, 2009, 10, 19921996.

68 S. Katz, R. P. Beatson and A. M. Scallan, Sven. Papperstidn., 1984, 87, 48-53.

69 N. T. Cervin, E. Johansson, J.-W. Benjamins and L. Wågberg, Biomacromolecules, 2015, 16, 822-831.

70 E. Larsson, C. C. Sanchez, C. Porsch, E. Karabulut, L. Wågberg and A. Carlmark, Eur. Polym. J., 2013, 49, 26892696.

71 H. Fukuzumi, T. Saito, T. Iwata, Y. Kumamoto and A. Isogai, Biomacromolecules, 2008, 10, 162-165.

72 M. Henriksson, L. A. Berglund, P. Isaksson, T. Lindström and T. Nishino, Biomacromolecules, 2008, 9, 1579-1585. 